\title{
IDENTIFIKASI DERAJAT HIPERTENSI PADA PASIEN HIPERTENSI DI PUSKESMAS KOTA MATARAM
}

\author{
Dewi Nur Sukma Purqoti ${ }^{1}$, Mira Utami Ningsih ${ }^{2}$ \\ ${ }^{1}$ Program Studi SI Ilmu Keperawatan Stikes Yarsi/Indonesia \\ ${ }^{2}$ Jurusan Keperawatan Poltekkes Kemenkes Mataram/Indonesia
}

\begin{abstract}
Abstrak
Terjadinya transisi epidemiologi yang paralel dengan transisi demografi dan transisi teknologi di Indonesia dewasa ini telah mengakibatkan perubahan pola penyakit dari penyakit infeksi ke Penyakit Tidak Menular (PTM) meliputi penyakit degeneratif dan man made diseases yang merupakan faktor utama masalah morbiditas dan mortalitas. Salah satu Penyakit Tidak Menular yang menjadi masalah kesehatan yang sangat serius saat ini adalah hipertensi yang disebut sebagai the silent killer. Upaya- upaya dalam menangani kasus hipertensi dengan cara terapi farmakologi dan non farmakologi. Tujuan penelitian ini adalah teridentifikasi derajat Hipertensi pada pasien hipertensi di puskesmas kota mataram. Penelitian ini merupakan penelitian yang bersifat deskriptif dengan pendekatan cross sectional. Tehnik pengambilan sampel yang digunakan yakni dengan Purposive Sampling. Analisa data yang digunakan adalah univariat dengan data disajikan dalam bentuk narasi, tabel distribusi frekuensi dan persentase. Hasil penelitian didapatkan rata-rata responden dalam penelitian ini berusia 50 sampai dengan 64 tahun (48.48\%), dilihat dari jenis kelamin mayoritas perempuan $(66.67 \%)$, mayoritas berpendidikan SD (48.48\%), dan sebagian besar bekerja sebagai Ibu Rumah Tangga $(45.45 \%)$ dan rata-rata untuk drajat hipertensi responden dalam penelitian ini dalam kategori Grade $1(66.7 \%)$. Kesimpulan dalam penelitian ini masih tingginya kasus hipertensi Sehingga dibutuhkan upaya kolaboratif antara keluarga dan pelayan kesehatan untuk menjaga tekanan darah agar tetap stabil dalam rentang normal.
\end{abstract}

Kata Kunci : Hipertensi, Derajat Hipertensi, Descriptive

\section{IDENTIFICATION OF THE DEGREE OF HYPERTENSION AMONG PATIENTS WITH HYPERTENSION IN THE MATARAM CITY HEALTH CENTERS}

\begin{abstract}
The occurrence of epidemiological transition that is parallel with the demographic transition and technological transition in Indonesia today has resulted in changes in the pattern of diseases from infectious diseases to Non-Communicable Diseases (NCD) including degenerative diseases and man made diseases which are the main factors of morbidity and mortality problems. One noncommunicable disease which is a very serious health problem today is hypertension called the silent killer. The efforts in dealing with cases of hypertension including pharmacological and nonpharmacological therapy. The purpose of this study was to identify the degree of hypertension in hypertensive patients in the Mataram City Health Center. This research is a descriptive study with cross sectional approach. The sampling technique used is Purposive Sampling. Analysis of the data used is univariate with data presented in the form of narratives, frequency distribution tables and
\end{abstract}


percentages. The results showed the average respondent in this study aged 50 to 64 years $(48.48 \%)$, seen from the gender of the majority of women $(66.67 \%)$, the majority of elementary school educated (48.48\%), and most worked as housewives (45.45\%) and the average for the degree of hypertension of respondents in this study were in the Grade 1 category (66.7\%). Conclusions in this study are still high cases of hypertension, so it takes collaborative efforts between families and health care providers to keep a stable blood pressure within normal range.

\section{Keywords: Hypertension, Degree of Hypertension, descriptive}

\section{PENDAHULUAN}

Terjadinya transisi epidemiologi yang paralel dengan transisi demografi dan transisi teknologi di Indonesia dewasa ini telah mengakibatkan perubahan pola penyakit dari penyakit infeksi ke Penyakit Tidak Menular (PTM) meliputi penyakit degeneratif dan man made diseases yang merupakan faktor utama masalah morbiditas dan mortalitas. Terjadinya transisi epidemiologi ini disebabkan terjadinya perubahan sosial ekonomi, lingkungan dan perubahan struktur penduduk, saat masyarakat telah mengadopsi gaya hidup tidak sehat, misalnya merokok, kurang aktivitas fisik, makanan tinggi lemak dan kalori, serta konsumsi alkohol yang diduga merupakan faktor risiko PTM. Pada abad ke-21 ini diperkirakan terjadi peningkatan insidens dan prevalensi PTM secara cepat, yang merupakan tantangan utama masalah kesehatan dimasa yang akan datang. Salah satu PTM yang menjadi masalah kesehatan yang sangat serius saat ini adalah hipertensi yang disebut sebagai the silent killer (Rahajeng \& Tuminah, 2009) ${ }_{1}^{-}$evalensi kejadian hipertensi dilaporkan berbeda di seluruh dunia dengan prevalensi terendah dı uaerah pedalaman India (3,4\% pada laki-laki dan 6,8\% pada wanita) dan tertinggi di Polandia (68,9\% pada laki-laki dan $72,5 \%$ pada wanita). Kesadaran penderita bahwa mereka menderita hipertensi adalah sekitar $46 \%$ dan mengalami perbedaan dari 25,2\% di Korea hingga 75\% di Barbados. Sebanyak 10,7\% penderita hipertensi menjalani pengobatan untuk hipertensi sementara di Bardados angkanya mencapai 66\%. Penyakit hipertensi dalam keadaan terkontrol (tekanan darah < 140/90 sewaktu masih meminum obat antihipertensi) sejumlah 5,4\% di Korea sementara di Barbados sejumlah 58\%. Kesimpulan dari penelitian tersebut adalah hipertensi merupakan masalah besar di dunia terutamanya di negara berkembang (Sanjaya, 2016).

Menurut data WHO, di seluruh dunia sekitar 972 juta orang atau $26,4 \%$ orang di seluruh dunia mengidap hipertensi, angka ini kemungkinan akan meningkat menjadi 29,2\% di tahun 2025 . Dari 972 juta pengidap hipertensi 333 juta berada di negara maju dan 639 sisanya berada di negara berkembang, termasuk Indonesia (Zaenurrohmah 2017). Berdasarkan data Riskesdas tahun 2013, kejadian Hipertensi di Provinsi Nusa Tenggara Barat berada pada peringkat ke 15 dari 33 Provinsi yang ada di Indonesia yaitu sebanyak 24,3\%. Sedangkan Provinsi dengan penderita hipertensi tertinggi adalah Provinsi Bangka Belitung sebanyak 30,9\%, diikuti Provinsi Kalimantan Selatan 30,8\%, Kalimantan Timur 29,6\%, Jawa Barat 29,4 \%, Gorontalo 29,0\%. Dan Provinsi Papua merupakan Provinsi dengan kejadian hipertensi terendah di Indonesia yaitu sebanyak 16,8\% (Riskesdas, 2013). 
Menurut Black \& Hawks (dalam Putra (2016) Faktor risiko yang mempengaruhi kejadian hipertensi diklasifikasikan menjadi faktor yang tidak dapat dimodifikasi dan dapat dimodifikasi. Faktor yang tidak dapat dimodifikasi adalah riwayat keluarga dengan hipertensi, umur, jenis kelamin, dan etnis. Di sisi lain, faktor yang dapat dimodifikasi adalah nutrisi, stres, obesitas, dan zat berbahaya misalnya rokok dan konsumsi alkohol berlebih, serta aktivitas fisik (Putra,2016).

Berdasarkan data Riskesdas NTB tahun 2016 penyakit hipertensi mengalami kenaikan di tahun 2016 yaitu dari 2,97\% menjadi 3,04\%. Perubahan life style kearah negatif seperti kurang aktifitas fisik, lebih sering mengkonsumsi fast food, junk food dan faktor stress adalah beberapa faktor yang memicu tingginya angka kejadian hipertensi di Nusa Tenggara Barat Provinsi NTB dihadapkan pada masalah beban ganda. Di satu sisi kasus penyakit infeksi masih tinggi, namun disisi lain penyakit degeneratif juga meningkat. Selain itu perilaku masyarakat yang tidak sehat masih menjadi factor utama disamping lingkungan dan pelayanan kesehatan (Profil Kesehatan NTB,2016).

Berdasarkan data profil kesehatan Kota Mataram tahun 2015, Puskesmas Cakranegara merupakan Puskesmas dengan kunjungan penderita tertinggi diantara Puskesmas lainnya. Survey pendahuluan yang dilakukan oleh peneliti di wilayah kerja Puskesmas Cakranegara, dengan mewawancarai 10 penderita hipertensi yang berkunjung di Puskesmas Cakranegara, diperoleh informasi bahwa 6 diantaranya mengatakan sering sekali tekanan darahnya naik karena tidak teratur minum obat dan tidak pernah kontrol ke Puskesmas. Mereka juga mengatakan jika tekanan darah sedang naik, mereka merasakan sakit pada tengkuk, pusing, terasa mau jatuh jika berjalan. Kemudian 3 penderita hipertensi mengatakan hanya mengeluh pusing dan lemas jika tekanan daranya naik, hal itu biasanya disebabkan karena pasien ada masalah rumah tangga yang sedang dipikirkan atau adanya berita/kejadian yang membuat pasien menjadi terkejut. Dan 1 diantara penderita mengatakan tidak mengeluh apa-apa jika tekanan darahnya naik, walaupun tekanan darahnya 200/110 mmHg, sehingga terkadang obat hipertensi yang di berikan tidak diminum. Penelitian ini bertujuan untuk teridentifikasi derajat Hipertensi pada pasien hipertensi di puskesmas Kota Mataram.

\section{METODE PENELITIAN}

Jenis penelitian ini adalah deskriptif dengan pendekatan cross sectional yaitu suatu jenis penelitian yang pengukuran variabel-variabelnya dilakukan hanya satu kali pada suatu saat. Populasi dalam penelitian ini adalah semua pasien yang menderita hipertensi derajat I sampai derajat II Pengambilan sampel dalam penelitian ini dengan pendekatan Purposive Sampling dengan jumlah sampel 33 responden, dengan kriteria inklusi Berusia antara 20-60 tahun, mampu berkomunikasi dengan baik, tidak memiliki penyait penyerta yang lain, dan bersedia berpatisipasi dalam penelitian (persetujuan dengan informed consent). Instrumen yang digunakan pada proses pengumpulan data dalam penelitian ini adalah lembar observasi, tensi meter (sphygmomanometer) dan stetoskop. Analisa data yang digunakan adalah Analisa data yang digunakan adalah univariat dengan data disajikan dalam bentuk narasi, tabel distribusi frekuensi dan persentase. 


\section{HASIL}

1. Karakteristik responden

Karakteristik responden yang ikut serta dalam penelitian meliputi: Umur, jenis kelamin, pendidikan, dan pekerjaan.

Tabel 1 Distribusi Responden berdasarkan umur di Puskesmas cakranegara tahun 2019

\begin{tabular}{ccc}
\hline Umur & N & Persentase \\
\hline $20-34$ & 2 & 6.07 \\
\hline $35-49$ & 15 & 45.45 \\
\hline $50-64$ & 16 & 48.48 \\
\hline Total & $\mathbf{3 3}$ & $\mathbf{1 0 0}$ \\
\hline
\end{tabular}

Sumber : Data primer 2019

Berdasarkan tabel 1 diatas menunjukkan bahwa rata-rata usia responden berada pada usia 50-64 tahun(48.48\%) .

Tabel 2 Distribusi Responden Berdasarkan Jenis Kelamin Di Puskesmas Cakranegara Tahun 2019

\begin{tabular}{llc}
\hline Jenis kelamin & N & Persentase \\
\hline Laki-laki & 11 & 33.33 \\
\hline Perempuan & 22 & 66.67 \\
\hline Total & $\mathbf{3 3}$ & $\mathbf{1 0 0}$ \\
\hline Sumber : Data primer 2019 & &
\end{tabular}

Berdasarkan tabel 2 diatas menunjukkan bahwa mayoritas responden dalam penelitian ini berjenis kelamin Perempuan yaitu sejumlah 22 orang (66.67\%).

Tabel 3 Distribusi Responden Berdasarkan Tingkat Pendidikan Di Puskesmas Cakranegara Tahun 2019

\begin{tabular}{|c|c|c|}
\hline Pendidikan & $\mathbf{N}$ & Persentase \\
\hline Tidak Sekolah & 3 & 9.10 \\
\hline SD & 16 & 48.48 \\
\hline SMP & 8 & 24.24 \\
\hline SMA & 6 & 18.18 \\
\hline Total & 33 & 100 \\
\hline
\end{tabular}

Berdasarkan tingkat pendidikan, distribusi responden menunjukkan sebagian besar responden berpendidikan SD yaitu sejumlah 16 orang (48.48\%).

Tabel 4 Distribusi Responden berdasarkan pekerjaan di Puskesmas cakranegara tahun 2019

\begin{tabular}{lcc}
\hline \multicolumn{1}{c}{ Pekerjaan } & N & Persentase \\
\hline Ibu Rumah Tangga & 15 & 45.45 \\
\hline Petani & 2 & 6.06 \\
\hline Pedagang & 6 & 18.18 \\
\hline
\end{tabular}




\begin{tabular}{lcc}
\hline Buruh & 8 & 24.24 \\
\hline Pegawai Swasta & 2 & 6.06 \\
\hline Total & $\mathbf{3 3}$ & $\mathbf{1 0 0}$ \\
\hline Sumber : Data primer 2019 & &
\end{tabular}

Distribusi pekerjaan responden menunjukkan sebagian besar responden bekerja sebagai Ibu Rumah Tangga (IRT) yaitu sejumlah 15 orang (45.45\%).

2. Derajad Hipertensi Responden

Tabel 5 Distribusi Responden Berdasarkan Derajat Hipertensi Di Puskesmas Cakranegara Tahun 2019

\begin{tabular}{cccc}
\hline \multicolumn{1}{c}{ Derajat Hipertensi } & F & Persentase \\
\hline Grade 1 & 22 & 66.7 \\
\hline Grade 2 & Total & 11 & 33.3 \\
\hline & 33 & $\mathbf{1 0 0}$
\end{tabular}

Sumber : Data primer 2019

Distribusi responden berdasarkan Derajat Hipertensi mayoritas terdapat pada kategori Grade I yang berjumlah 22 orang atau $(66.7 \%)$.

\section{PEMBAHASAN}

\section{Karakteristik Responden}

Berdasarkan data usia, responden dalam penelitian ini di dominasi oleh responden usia antara 50 - 64 tahun yaitu sebanyak 16 orang. Menurut Rahajeng dan Tuminah (2009), tingginya hipertensi sejalan dengan bertambahnya umur yang disebabkan oleh perubahan struktur pada pembuluh darah besar, sehingga pembuluh darah menjadi lebih sempit dan dinding pembuluh darah menjadi kaku, sebagai akibatnya adalah meningkatnya tekanan darah sistolik. Selain usia pra lansia, usia dewasa muda yaitu > 20 tahun banyak yang mengalami hipertensi. Hal ini dapat dipengaruhi oleh stressor yang tinggi. Hal ini sejalan dengan pendapat Pickering (2008) dalam Arifia (2010), mengatakan bahwa laki-laki dewasa muda yang bekerja dalam kondisi pekerjaan dengan stress yang tinggi dapat meningkatkan tekanan darah tidak hanya selama jam kerja, akan tetapi setelah tiba di rumah bahkan saat tidur.

Pada penelitian ini subjek yang banyak mengalami hipertensi adalah perempuan. Hal ini di karenakan responden perempuan lebih antusias dalam mengikuti kegiatan agama maupun kegiatan-kegiatan yang dapat menambah wawasannya. Ini sejalan dengan hasil wawancara peneliti kepada responden perempuan yang mengatakan perempuan itu lebih antusias dan senang ketika ada kegiatan agama maupun kegiatan yang dapat menambah wawasannya. Dari pada kaum bapak-bapak kurang begitu antusias, karena mereka sibuk bekerja dan alas an lainnya. Menurut Singalingging (2011) dalam Novitaningtyas (2014), rata-rata perempuan akan mengalami peningkatan resiko tekanan darah tinggi setelah menopause yaitu usia diatas 45 tahun. Penelitian 
ini juga di dominasi oleh responden dengan tingkat pendidikan Sekolah Dasar, yakni sebanyak 16 orang $(48,48 \%)$.

Sebagian besar responden berpendidikan SD yaitu sejumlah 16 orang (48.48\%). Semakin tinggi pendidikan seseorang maka semakin mudah dalam menerima informasi sehingga semakin banyak pula pengetahuan yang dimiliki dan kemampuan dalam menghadapi masalah serta menganalisa situasi akan lebih baik yang pada akhirnya dapat memilih tindakan secara tepat dalam menghadapi sebuah masalah. Berdasarkan penelitian Wahyuni dan Eksanoto (2013) dalam Novitaningtyas (2014), membuktikan bahwa ada hubungan yang signifikan antara tingkat pendidikan dengan kejadian hipertensi, nilai $\mathrm{p}=0,000$. Pada penelitian tersebut sebanyak 58,5\% subjek dalam kategori tingkat pendidikan rendah mengalami hipertensi, sebanyak 4,3\% subjek dalam kategori tingkat pendidikan menengah mengalami hipertensi, dan sebanyak 3,9\% subjek dalam kategori tingkat pendidikan tinggi mengalami hipertensi.

Penelitian ini juga didominasi oleh responden yang bekerja sebagai ibu rumah tangga. Ibu rumah tangga yang pekerjaannya sehari-hari dirumah tentunya dapat menimbulkan stress yang dapat memicu terjadinya naiknya tekanan darah. Pengosongan sementara pikiran terhadap masalah psikososial memungkinkan terjadinya penurunan rangsang terhadap stresor. Penurunan rangsang terhadap stresor kemudian direspon oleh hipotalamus dengan menurunkan pengaturan sekresi hormone kortison, epinefrin dan norepinefrin dalam pembuluh darah.

\section{Data Derajad Hipertensi Responden}

Berdasarkan Derajat Hipertensi mayoritas responden berada pada kategori Grade I yaitu berjumlah 22 orang $(66.7 \%)$. Dalam hal ini, grade hipertensi dapat meningkat atau tetap, bisa dipengaruhi oleh perawatan yang didapat oleh responden. Perawat memandang klien sebagai makhluk bio-psiko-sosio-kultural dan spiritual yang berespon secara unik terhadap perubahan kesehatan atau pada keadaan krisis. Berdasarkan teori adaptasi Roy yaitu perawat harus mampu meningkatkan respon adaptif pasien pada situasi sehat atau sakit. Perawat dapat mengambil tindakan untuk memanipulasi stimulus fokal, kontekstual maupun residual dengan melakukan analisis sehingga stimuli berada pada rentang adaptif. Perawat harus mampu bertindak untuk mempersiapkan pasien dan keluarga mampu mengantisipasi perubahan melalui penguatan regulator, kognator dan mekanisme koping (Margono, 2012).

Selain itu, terdapat faktor lain yang memungkinkan mempunyai efek terhadap bagaimana pasien berespon terhadap stressor yang dialaminya. Dilihat dari Usia responden pada kelompok kontrol usia rata-rata 63 tahun, semakin cukup usia seseorang maka semakin bayak pengalaman yang dimiliki dalam mengatasi stresor. Pendidikan juga memberikan sumbangsih dalam mengatasi stresor, semakin tinggi pendidikan seseorang maka semakin maka semakin tinggi pengetahuannya sehingga kemampuan dalam menghadapi masalah, menganalisa situasi, dan pada akhirnya memilih tindakan yang tepat dalam menghadapi suatu masalah (Stuart \& Suddeen, 2006). 
Dukungan keluarga juga memberikan kontribusi dalam meningkatkan kemampuan adaptasi pasien, dimana pada keluarga responden selalu menemani dan memberikan suport kepada klien agar tetap semangat dalam menjalani pengobatan.

\section{KESIMPULAN}

Berdasarkan hasil penelitian, maka dapat disimpulkan bahwa rata-rata responden dalam penelitian ini berusia 50 sampai dengan 64 tahun, mayoritas merupakan Perempuan 22 orang (66.67\%). Responden penelitian sebagian besar lulusan SD yaitu sebanyak 16 orang (48.48\%) dan sebagian besar bekerja sebagai Ibu Rumah Tangga (IRT) yaitu sejumlah 15 orang (45.45\%). Derajat Hipertensi mayoritas responden yaitu pada kategori Grade I, sebanyak 22 orang (66.7\%).

Hasil penelitian ini menunjukkan perlunya meningkatkan pengetahuan pasien dan keluarga pasien tentang hipertensi terutama untuk mencegah grade hipertensi menjadi lebih tinggi. Dukungan keluarga juga sangat diperlukan, keluarga dapat menjadi support system bagi pasien terutama untuk menjaga kepatuhan minum obat. Namun keluarga juga dapat menjadi sumber stress atau stressor yang memperburuk prognosis pasien. Sehingga diperlukan juga pendampingan secara berkelanjutan bagi pasien dan keluarga untuk meningkatkan kesadaran pasien Hipertensi dalam mempertahankan kondisi tetap stabil.

\section{DAFTAR PUSTAKA}

Arifia.2010.Faktor- faktor yang Berhubungan dengan kejadian Hipertensi di Provinsi DKI Jakarta.skripsi.Jakarta:UI Di Unduh dari eprints.ums.ac.id/29089/9/06._naskah_publikasi.pdf.

Novitaningtyas,tri.2014.Hubungan Karekteristik (Umur,Jenis Kelamin, Tingkat Pendidikan) Dan Aktivitas Fisik Dengan Tekanan Darah Pada Lansia Di Kelurahan Makam Haji Kecamatan Kartasura Kabupaten Sukoharjo.Universitas Surakarta. Di Unduh dari eprints.ums.ac.id/29084/9/02._naskah_publikasi.pdf.

Profil Kesehatan Provinsi NTB. 2016. di unduh dari www.depkes.go.id/ resources/ download/profil/PROFIL_KES...2016/18_NTB_2016.pdf pada tanggal 25 April 2018 pukul 17.20 WITA

Profil Kesehatan Kota Mataram. 2015. Di unduh dari http://www.depkes.go.id/ resources/download/profil/PROFIL_KAB_KOTA_2015/5271_NTB_Kota_Mataram_ 2015.pdf. pada tanggal 25 April 2018 pukul 17.20 WITA.

Putra \& Ulfah.2016. Analisis Faktor Risiko Hipertensi Di Puskesmas Kelayan Timur Kota Banjarmasin.Vol. 1, No 2. Di unduh dari https://scholar.google.co.id/ citations?user=7okvgw4AAAAJ\&hl=id. pada tanggal 25 April 2018 pukul 17.20 WITA.

Rahajeng \& Tuminah.2009.Prevalensi Hipertensi dan Determinannya di Indonesia. Vol.59, No 12. Di unduh dari http://egiwidiyaoktora201432049. weblog. esaunggul.ac.id/ 
wp-content/uploads/sites/4896/2015/09/700-760-1-PB.pdf pada tanggal 26 April 2018 pukul 16.00 WITA.

Ramadhan, A.J. 2010. Mencermati Berbagai Gangguan pada Darah dan Pembuluh Darah. Jogjakarta:DIVA Press.

Riskesdas Tahun 2013 di unduh dari www.depkes.go.id/resources/download/general/ Hasil\%20Riskesdas\%202013.pdf pada tanggal 25 April 2018 pukul 17.30 WITA.

Sanjaya, I Made Artha Wiguna.2017.Prevalensi Hipertensi Pada Penduduk Umur 30 Tahun Hingga 80 Tahun Di Kecamatan Tembuku Bangli Bali Tahun 2013. Vol.5, No 6. Di unduh dari https://ojs.unud.ac.id/index.php/ eum/article/view/21108/13886. pada tanggal 25 April 2018 pukul 17.30 WITA.

Zaenurrohmah \& Rachmayanti.2017. Hubungan Pengetahuan Dan Riwayat Hipertensi Dengan Tindakan Pengendalian Tekanan Darah Pada Lansia. Di unduh dari https://ejournal.unair.ac.id/JBE/article/download/3886/3895 pada tanggal 25 April 2018 pukul 17.30 WITA. 